\title{
Not all risks are equal: The risk taking inventory for high-risk sports
}

\author{
Woodman, Tim; Barlow, M.D.; Bandura, C.; Hill, M.L.; Kupciw, D.; Macgregor, A.
}

\section{Journal of Sport and Exercise Psychology}

Published: 21/08/2013

Peer reviewed version

Cyswllt i'r cyhoeddiad / Link to publication

Dyfyniad o'r fersiwn a gyhoeddwyd / Citation for published version (APA):

Woodman, T., Barlow, M. D., Bandura, C., Hill, M. L., Kupciw, D., \& Macgregor, A. (2013). Not all risks are equal: The risk taking inventory for high-risk sports. Journal of Sport and Exercise Psychology, 35(5), 479-492.

\footnotetext{
Hawliau Cyffredinol / General rights

Copyright and moral rights for the publications made accessible in the public portal are retained by the authors and/or other copyright owners and it is a condition of accessing publications that users recognise and abide by the legal requirements associated with these rights.

- Users may download and print one copy of any publication from the public portal for the purpose of private study or research.

- You may not further distribute the material or use it for any profit-making activity or commercial gain

- You may freely distribute the URL identifying the publication in the public portal ?

Take down policy

As accepted for publication

Take down policy

If you believe that this document breaches copyright please contact us providing details, and we will remove access to the work immediately and investigate your claim.
} 
Article accepted in its current form in Journal of Sport \& Exercise Psychology:

Woodman, T., Barlow, M., Bandura, C., Hill, M., Kupciw, D., \& MacGregor, A. (2013). Not all risks are equal: The risk-taking inventory for high-risk sports. Journal of Sport $\&$ Exercise Psychology, 35, 479-492

Not all risks are equal: The risk-taking inventory for high-risk sports

Tim Woodman, Matt Barlow, Comille Bandura, Miles Hill, Dominika Kupciw and Alexandra MacGregor

Bangor University

Correspondence concerning this article should be addressed to: Tim Woodman, Institute for the Psychology of Elite Performance, Bangor University, Bangor, Gwynedd, LL57 2DG, UK. Telephone: +44 1248382 756. Fax: +44 1248371 053. Email: t.woodman@bangor.ac.uk

Acknowledgement: The authors would like to thank David Markland for his assistance with data analysis in Study 1. 


\begin{abstract}
Although high-risk sport participants are typically considered a homogenous risk-taking population, attitudes to risk within the high-risk domain can vary considerably. As no validated measure allows researchers to assess risk-taking within this domain, we validated the Risk-Taking Inventory (RTI) for high-risk sport across four studies. The RTI comprises seven items across two factors: deliberate risk-taking and precautionary behaviors. In Study $1(n=341)$, the inventory was refined and tested via a confirmatory factor analysis used in an exploratory fashion. The subsequent three studies confirmed the RTI's good model-data fit via three further separate confirmatory factor analyses. In Study $2(n=518)$ and in Study 3 ( $n$ $=290$ ), concurrent validity was also confirmed via associations with other related traits (sensation seeking, behavioral activation, behavioral inhibition, impulsivity, self-esteem, extraversion, and conscientiousness). In Study $4(n=365)$, predictive validity was confirmed via associations with mean accidents and mean close-calls in the high-risk domain. Finally, in Study 4, the self-report version of the inventory was significantly associated with an informant version of the inventory. The measure will allow researchers and practitioners to investigate risk-taking as a variable that is conceptually distinct from participation in a highrisk sport.
\end{abstract}

Keywords: self-esteem; extraversion; conscientiousness; sensation seeking; impulsiveness; precautionary behaviors 
Not all risks are equal: The risk-taking inventory for high-risk sports The secret for harvesting from existence the greatest fruitfulness and greatest enjoyment is: to live dangerously! - Friedrich Nietzsche (1882)

High-risk sports are defined as those in which participants accept the possibility of severe injury, or even death, as an inherent part of engagement (Breivik, 1996). Thus, by definition, high-risk sportspeople are risk-takers; they purposefully put themselves in at least some danger. Although some individuals appear purposefully to increase the exposure to danger by engaging deliberately in additional risk-taking behaviors whilst participating in high-risk sport (e.g., Llewellyn \& Sanchez, 2008; Slanger \& Rudestam, 1997), many highrisk sport participants engage with the express desire to minimize and control the dangers inherent in the high-risk domain by exhibiting precautionary behaviors (e.g., Celsi, Rose \& Leigh, 1993; Pain \& Pain, 2005). Alex Lowe, widely considered one of his generation's finest all-around mountaineers (Gutman \& Frederick, 2003), illustrates this attitude to danger:

There's a fascination and an appeal in [mountaineering] in a situation that's potentially risky, but rather than being a risk taker as such, I consider myself and my climbing peers to be risk controllers, and we just enjoy being in this situation and keeping risk at a reasonable level (Gutman \& Frederick, 2003, p. 93).

Thus, risk-taking in high-risk sport does not appear to be a unitary phenomenon, but rather comprises two contrasting behaviors: deliberate risk-taking and precautionary behaviors. These factors can be conceptualized as orthogonal in nature (cf. Paquette, Lacourse, \& Bergeron, 2009). For example, a rock climber might purposefully climb a steep rock face without a rope (deliberate risk-taking) and yet adopt a number of precautionary measures (e.g., reconnoiter the rock face very carefully, check the weather, etc.).

Given the potentially life-threatening consequences of deliberately courting danger in the high-risk sport domain, it is important to identify those individuals likely to adopt such 
deliberate risk-taking behaviors. Furthermore, it is important to gain a greater understanding of the motives that underpin engagement in both deliberate risk-taking behaviors and precautionary behaviors in the high-risk sport domain (e.g., Castanier, Le Scanff, \& Woodman, 2010a). Despite the importance of this topic, research in this area has been limited by the lack of a suitable measure of risk-taking attitudes and behaviors in the high-risk domain and has relied on one-dimensional and largely un-validated measures of risk-taking behaviors (e.g., Lafollie \& Le Scanff, 2007). As such, there remains a need in the literature for a scale that measures risk-taking behaviors in the high-risk domain across a variety of high-risk sports. The aim of the present research was to develop such a self-report measure, the Risk-Taking Inventory (RTI).

Furthermore, if the RTI is to be a valid psychometric measure of risk-taking attitudes and behaviors, it should predict risk-associated outcomes in the high-risk domain. In previous research, accidents and acute injuries have been conceptualized as a measure of risk-taking per se (e.g., Castanier et al., 2010b; Cherpitel, Meyers \& Perrine, 1998; Cogan \& Brown, 1999). However, such an approach lacks conceptual precision, as individuals who deliberately expose themselves to danger may repeatedly experience life-threatening "closecalls" yet largely avoid accidents and injury. Conversely, an individual who takes precautions in order to minimize danger may experience accidents as a consequence of uncontrollable conditions (e.g., weather conditions, the behavior of others, etc.). Consequently, in the final study we asked participants to report their experience of accidents and their experience of close-calls throughout their involvement in their chosen high-risk sport. Close-calls are incidents that come very close to resulting in a negative outcome but that fail to materialize into a negative outcome. As such, close-calls are largely the same as an accident except for the outcome. It can be argued that close-calls (compared to accidents) are a somewhat more 
refined measure of the potential outcome of risk-taking behaviors, as they account for other less controllable variables (e.g., luck).

As a combination of data sources increases the validity and reliability of personality assessments (Vazire, 2006), we also used informant ratings as a second source of assessing participants' risk-taking behaviors. To this end, we modified the RTI such that an observer could rate a participant on his/her risk-taking behaviors. Such observer ratings of personality traits have been employed effectively in previous research (e.g., Oh, Wang, \& Mount, 2011) and have been shown to predict future performance over and above self-report measures (Mount, Barrick, \& Strauss, 1994).

Finally, it is worth noting at this juncture that we use the terms "attitude" and "behavior" fairly interchangeably despite their being distinct constructs. This is because it is ultimately the "behavior" that is of interest in the high-risk domain. In other words, it would be of theoretical and applied interest to know specifically who "takes risks" in an already dangerous environment. However, one clearly cannot measure specific risk behaviors via an inventory; one can measure only the attitude and associated propensity to risk. As such, we are limited to measuring the attitudes and the propensity for certain behaviors within the framework of a self-report measure of risk-taking (cf. Rohrmann, 1998).

\section{Study 1}

A promising exploratory step toward creating and validating a measure of high-risk sport participants' risk attitudes and behaviors was taken by Paquette et al. (2009), who explored the factor structure of a three-factor model of risk-taking in adolescent skiers and snowboarders. Although promising, the scale focused solely on this specific population and thus cannot be generalized to participants of other high-risk sports or adults. That said, both deliberate risk-taking and precautionary behaviors emerged as discriminant factors in their 
exploratory analyses. The aim of Study 1 was to develop and validate a measure of risktaking behaviors that is applicable to high-risk sport participants in general.

\section{Method}

Participants. The sample comprised 336 individuals who participated in a range of high-risk sports (e.g., skydiving, mountaineering, extreme skiing, traditional rock climbing, etc.). Since experienced adults have been shown to demonstrate greater accuracy in differentiating risky behaviors (Kontos, 2004), the eligibility criteria for participation in the present research were to be at least 18 years old and to have at least three years' participatory experience in high-risk sport.

Participants were recruited via internet advertisements placed on specific sporting websites (e.g., goneboarding.co.uk and ukclimbing.co.uk). The chance to win $£ 30$ (approximately US\$48) on completion of the online inventories was offered as an incentive. List-wise deletion procedures were applied to deal with missing data, which removed data from 31 participants. List-wise deletion was considered appropriate across all four studies given that the data were assumed to be missing at random with no more than four participants $(1.17 \%)$ with missing data on a single variable within a given data set (Peng, Harwell, Liou, \& Ehman, 2006; Tabachnick \& Fidell, 2001). The final sample for Study 1 comprised 305 individuals ( 259 men, 46 women; $M_{\mathrm{age}}=30.43, S D=9.78 ; M_{\text {years participation }}=9.31, S D=9.03$ ).

Measures. The initial Risk Taking Inventory (RTI) comprised two proposed factors: deliberate risk-taking (80 items) and precautionary behaviors (83 items). Items were developed following a review of both the high-risk sport media (autobiographies, DVDs, etc.) and the current scientific research pertaining to risk-taking behaviors in high-risk sport (e.g., mountaineering, motocross, free-running, skydiving, etc.). The aim of the review was to identify both prevalent deliberate risk-taking behaviors and prevalent precautionary behaviors across a wide-variety of high-risk sports and to insure content validity of the proposed scale. 
The nature of the media abstraction resulted in items that were initially domainspecific. Example items included, "I always check my rope prior to climbing" (traditional rock-climbing) and "I always double-check my lines prior to launch" (paragliding). When prominent themes emerged across multiple sports, items were combined and modified to remove domain/sport specificity. Thus, in the two examples above, the resultant item became, "I check my equipment is in good condition." Following this process 42 items (Deliberate risk-taking $=20$; Precautionary behaviors $=22$ ) were retained. Two independent academic peers, with expertise in the subject area, acted as "judges" (Wynd, Schmidt \& Schaefer, 2003, p. 509) to provide content-validation of the remaining 42 items.

Next, we conducted semi-structured pilot interviews with 14 experts from a variety of high-risk activities: mountaineering $(n=3)$, rock climbing $(n=5)$, white-water kayaking $(n=$ 4), and skydiving ( $n=2)$. One question, for example, required each expert to "select the 10 items that resonate most strongly with you, regarding your participation in high-risk sport." These interviews allowed the research team to retain items with the greatest face validity (Goodwin, 2009). Subsequently, 10 items pertaining to deliberate risk taking (e.g., I deliberately put myself in danger) and 10 items pertaining to precautionary behaviors (e.g., I take time to check for potential hazards) were retained. Inventory items were presented alternately by factor and participants were asked to respond to each statement on a five-point Likert scale $(1=$ never $; 5$ always $)$.

Procedure. The use of online questionnaires was deemed particularly appropriate in the present research, as they have been shown to: generate greater self-disclosure from participants (Stanton, 1998); result in lower scores on social desirability measures compared to pen-and-paper alternatives (Joinson, 1999); and remove potential error that is inherent in paper-computer transcription (Mangunkusumo et al., 2005). Recruitment adverts led participants to a webpage providing details of the research, a confidentiality agreement, and a 
notification that proceeding to the next webpage was an expression of informed consent to participate. If they chose to continue, participants completed demographic data followed by the 20 -item version of the RTI. When responding to the questions participants were asked to think about their favorite high-risk sport. The whole procedure took approximately 15 minutes.

Analyses. Data were analyzed using confirmatory factor analysis (CFA) partially in an exploratory fashion. Continuous variable CFA methods were deemed appropriate since the ordered-categorical data comprised five categories (Rhemtulla, Brosseau-Liard, \& Savalei, 2012). Prelis 2.14 (Jöreskog \& Sörbom, 2003) was used to generate a covariance matrix and Lisrel 8.54 (Jöreskog \& Sörbom, 2003) was used to test the models. A model was considered a good fit to the data if the Comparative Fit Index (CFI, Bentler, 1990) and the Non-Normed Fit Index (NNFI, Tucker \& Lewis, 1973) were greater than or equal to .95; the Root Mean Square Residual (RMSEA, Steiger \& Lind, 1980) was less than or equal to .06; the Standardized Root Mean Square Residual (SRMR, Bentler, 1990) was less than or equal to .08 ; and the Satorra-Bentler (S-B) $\chi^{2} / \mathrm{df}$ ratio was less than 2.00 .

All models that used the data set of complete cases (i.e., following list-wise deletion) were compared to the equivalent models that used the data set with full information maximum likelihood (FIML) estimations applied (see Table 1). As these comparisons confirmed that model fit was not markedly different across methods (Little \& Rubin, 1987) we proceeded with each data set of complete cases.

\section{Results}

Based on recommendations in the literature (e.g., Jöreskog, 1993) the two factors deliberate risk-taking (DRT) and precautionary behaviors (PB) - were initially examined individually in order to retain only those items that were good indicators of their underlying latent variable. Post-hoc model modifications were carried out by examination of the 
standardized residuals, factor loadings, modification indices for Theta-delta, and theoretical considerations. Low factor loadings $(<.40)$ demonstrated that items were poor indicators of their underlying factor, and problem residuals $(>+2.00$ or $<-2.00)$ meant that the model was either under- or over-parameterized (Byrne, 1998). Single-factor CFA results, for both DRT and PB (see Table 1), indicated that the fit of the models to the data could be significantly improved by removing certain items. This process reduced the number of items retained from 10 to 8 for both DRT and PB.

The two factors were then examined together in order to examine the psychometric integrity of each factor in the presence of the other factor. The aim was to retain only those items that clearly loaded on the appropriate factor and to delete any ambiguously loading items. Two-factor CFA results (see Table 1) indicated that the fit of the model to the data could again be significantly improved by removing further items. This process led to the retention of seven items $(\mathrm{DRT}=3 ; \mathrm{PB}=4)$.

Testing the two-factor seven-item full-model revealed a good fit (see Table 1). Factorfactor correlations (-.30) supported the discriminant validity between DRT $(M=7.39, S D=$ 2.63) and $\mathrm{PB}(M=16.42, S D=2.85)$. Internal consistency and item homogeneity of the two factors were assessed using both the traditional coefficient alpha and composite reliability, which has been shown to produce a better estimate of true reliability than coefficient alpha (Peterson \& Kim, 2013). The subscales demonstrated acceptable alpha reliability (DRT = .69; $\mathrm{PB}=.73)$ and acceptable composite reliability $(\mathrm{DRT}=.78 ; \mathrm{PB}=.71)$. The item-factor loadings for each subscale are displayed in Table 2.

\section{Discussion}

The aim of Study 1 was to develop an inventory - the RTI - to measure deliberate risk-taking and precautionary behaviors in the high-risk sport domain. Following removal of ambiguous items, based on a priori criteria, fit indices suggested that the final full model fit 
the data well. Additionally, when comparing results from the list-wise deleted data set against those obtained with FIML estimations, model fit was not markedly different. In summary, the two-factor structure of the seven-item version of the RTI was supported.

\section{Study 2}

The aim of Study 2 was twofold: (a) to confirm the factor structure of the RTI; and (b) to establish concurrent validity. We considered three constructs for these validation purposes.

Behavioral Inhibition and Behavioral Activation. Gray $(1972,1981)$ proposed two dimensions of personality: one that regulates aversive motivation, and one that regulates appetitive motivation. The aversive motivational system is called the behavioral inhibition system (BIS) and is sensitive to signals of punishment and non-reward, thereby inhibiting behavior that may lead to negative or painful outcomes (Carver \& White, 1994). Precautionary behaviors may arise, in part, from a participant's sensitivity to the "punishment" associated with failure in the high-risk domain (i.e., the possibility of severe injury or death). As such, we hypothesized that BIS would be positively correlated with PB.

The appetitive motivational system has been called the behavioral activation system (BAS) and is sensitive to signals of reward and non-punishment, thereby increasing an individual's proneness to seek out feelings of elation and happiness (Gray, 1981). Research suggests that, in the high-risk domain, an express desire for rewarding stimuli and "sensation rewards" is associated with an elevated willingness to take physical risks (Zuckerman, 2007). As such, we hypothesized that BAS would be positively associated with DRT.

Sensation Seeking. Individuals with elevated scores on measures of sensation seeking are hypothesized to seek intensity and novelty in sensory experience (Zuckerman, 1994). Indeed, it is proposed that such individuals - labeled sensation seekers - are willing to take deliberate physical risks in order to experience the sensation rewards of risky activities (Zuckerman, 2007). High sensation seekers tend voluntarily to engage more than low 
sensation seekers in drug research, gambling, and jobs involving high levels of risk (Musolino \& Hershenson, 1977; Zuckerman, 1979). We hypothesized that sensation seeking would be significantly positively correlated with DRT.

Impulsivity. Impulsivity is one of the strongest personality correlates of various voluntary deliberate risk-taking behaviors such as alcohol abuse (Nagoshi, Wilson, \& Rodriguez, 1991), drug abuse (Butler \& Montgomery, 2004), and risky sexual practices (Donohew et al., 1999). Impulsive behaviors reflect urgency and involve acting on the spur of the moment, disregarding the consequences of one's actions, and an inability to sustain focus on disinteresting tasks. Conversely, perseverance and premeditation require planning, forethought, and a careful approach to a task (Magid \& Colder, 2007). As such, we hypothesized that impulsivity would be positively associated with DRT and negatively associated with PB.

\section{Method}

Participants. The sample comprised 518 new participants ${ }^{1}$ recruited using the same method and inclusion criteria described in Study 1. The diversity of sports represented, and the participant experience therein, closely resembled that of Study 1. Nineteen participants were removed due to incomplete data and a further nine participants did not meet the eligibility criteria. The final sample comprised 490 individuals (400 men, 90 women; $M_{\text {age }}=$ $\left.35.69, S D=10.21 ; M_{\text {years participation }}=14.36, S D=10.01\right)$.

\section{Measures}

Risk-Taking Inventory. The seven-item Risk-Taking Inventory (RTI) developed in Study 1 measured deliberate risk-taking behaviors (DRT) and precautionary behaviors (PB).

The BIS/BAS Scale. Carver and White's (1994) measure comprises four scales each answered on a four-point Likert scale ( $1=$ strongly agree; $4=$ strongly disagree $)$. The

\footnotetext{
${ }^{1}$ Checking the email addresses of all participants across all four studies revealed that participants across the four studies participated in one study and in one study only.
} 
Behavioral Inhibition System (BIS) scale references reactions to the anticipation of, or sensitivity to, punishment (seven items; e.g., I worry about making mistakes). Unlike the onedimensional BIS scale there are three separate scales related to the Behavioral Activation System (BAS). BAS-Drive reflects the persistent pursuit of desired goals (four items; e.g., I go out of my way to get things I want). BAS-Fun Seeking reflects both a desire for new rewards and a willingness to approach a potentially rewarding event on the spur of the moment (four items; e.g., I crave excitement and new sensations). BAS-Reward Response focuses on positive responses to the occurrence or anticipation of reward (four items; e.g., It would excite me to win a contest).

Brief Sensation Seeking Scale. The Brief Sensation Seeking Scale (BSSS; Hoyle, Stephenson, Palmgreen, Lorch \& Donohew, 2002) was designed to be a brief version of Zuckerman's (1979) Sensation Seeking Scale and measures four dimensions of sensation seeking, on a five-point Likert scale ( 1 = strongly disagree; 5 = strongly agree $)$. The four dimensions - each consisting of two items - are: Experience Seeking (ES; e.g., I would like to explore strange places); Boredom Susceptibility (BS; e.g., I get restless when I spend too much time at home); Disinhibition (DIS; e.g., I like wild parties); Thrill and Adventure Seeking (TAS; e.g., I like to do frightening things).

UPPS Impulsive Behavior Scale. Magid and Colder's (2007) updated version of Whiteside and Lynam's (2001) scale measures Urgency (12 items; e.g., when I am upset I often act without thinking), Sensation Seeking (12 items; e.g., I quite enjoy taking risks), Premeditation (11 items, e.g., I have a reserved and cautions attitude toward life), and Perseverance (10 items; e.g., unfinished tasks really bother me) on a five-point Likert scale (0 = Not at all; $4=$ Very much). The first two factors reflect impulsivity and the second two factors reflect its converse. 
Procedure. All participants completed a demographics questionnaire, as in Study 1, followed by the BSSS, UPPS, and RTI. The online presentation of the inventories mimicked that used in Study 1 and took approximately 25 minutes to complete.

\section{Results}

RTI model fit. A good fit for the two-factor, seven-item RTI model was confirmed (see Table 1). Factor-factor correlations confirmed the discriminant validity of the two-factor model (-.15).

Sex differences. An independent samples $t$-test revealed significant sex differences in DRT total-score, $t(154.15)=7.20 ; p<.001$, with men scoring significantly higher than women. Consequently, all variables in this study and subsequent studies reported in this paper were standardized within sex before further analysis. ${ }^{2}$

Concurrent validity: Deliberate risk-taking. As hypothesized, DRT was significantly positively correlated with all subscales of the BAS and the BSSS. Furthermore, as hypothesized, DRT was significantly negatively correlated with UPPS subscales premeditation and perseverance and significantly positively correlated with urgency. The correlations are presented in Table 3.

Concurrent validity: Precautionary behaviors. As hypothesized, PB was significantly correlated with all UPPS subscales. However, PB was not significantly correlated with BIS. The correlations are presented in Table 3. Interestingly, PB was positively associated with both BAS fun seeking $(r=.10, p=.02)$ and UPPS sensation seeking $(r=.16, p<.001)$. Given that we had hypothesized that BAS subscales would be associated more with DRT than with PB, we conducted a Steiger's (1980) Z-test between the DRT-BAS fun seeking and PB-BAS fun seeking correlations; BAS fun seeking was significantly more associated with DRT than with $\mathrm{PB}, Z=3.34, p<.01$, as hypothesized.

${ }^{2}$ The DRT sex difference was confirmed in Study 3 and in Study 4 (men scored higher than women): in Study 3, $t(131)=2.66 ; p=.009 ;$ in Study 4, $t(163)=3.14 ; p=.002$. 
Additionally, given that we had hypothesized that UPPS sensation seeking would be associated more with DRT than with PB, we conducted a Steiger's (1980) Z-test between the DRT-UPPS sensation seeking and PB- UPPS sensation seeking correlations; UPPS sensation seeking was significantly more associated with DRT than with $\mathrm{PB}, Z=2.70, p<.01$, as hypothesized.

\section{Discussion}

Study 2 confirmed the two-factor structure of the RTI. Furthermore, the concurrent validity of the RTI was confirmed against measures of sensation seeking, behavioral activation and inhibition, and impulsivity. Counter to the hypothesis, precautionary behaviors were not correlated with the BIS scale. This lack of association suggests that precautionary behaviors do not primarily serve to inhibit movement toward goals. Specifically, participants high in precautionary behaviors are not likely motivated by a fear of punishment or attempts to avoid negative or painful outcomes (cf. Carver \& White, 1994).

\section{Study 3}

Although Study 2 provided strong evidence for the concurrent validity of the DRT factor, the evidence for PB was somewhat less conclusive with only premeditation and perseverance (i.e., low impulsivity) positively correlated with precautionary behaviors. Consequently, Study 3 was developed to further clarify the concurrent validity of the RTI, and specifically which variables might predict precautionary behaviors rather than deliberate risk-taking. Self-esteem was deemed a likely candidate in that respect. Indeed, individuals with high self-esteem are thought to engage more readily in more or less risk-taking activities depending on the nature of the task and the literature reflects these mixed findings (cf. Baumeister, Heatherton, \& Tice, 1993; Seal, Minichiello, \& Omodei, 1997). As such, it is difficult to make a precise prediction about the relationship between self-esteem and deliberate risk-taking. Conversely, individuals with high self-esteem are most likely to adopt 
greater self-preservation measures in a high-risk domain. Self-esteem has indeed been shown to be associated with greater safety precautions (Paquette et al., 2009). As such, self-esteem should be more clearly and positively associated with precautionary behaviors than with deliberate risk-taking.

In studies of personality, conscientiousness has also been consistently associated with precautionary health behaviors (Hill \& Gick, 2011; Vollrath \& Torgersen, 2002). Conversely, low conscientiousness and high extraversion have been associated with risky health behaviors (Arthur \& Graziano, 1996; Wallace \& Vodanovich, 2003). As such, we hypothesized that conscientiousness would be positively associated with precautionary behaviors and negatively associated with deliberate risk taking. Finally, we hypothesized that extraversion would be positively associated with deliberate risk taking.

\section{Method}

Participants. The sample comprised 290 new participants recruited using the same method and inclusion criteria as described in Study 1. The diversity of sports represented, and the participant experience therein, closely resembled that of the previous two studies. Twenty-three participants provided incomplete data and 46 participants did not meet the inclusion criteria. The final sample comprised 221 individuals $\left(163\right.$ men, 58 women; $M_{\text {age }}=$ $\left.31.15, S D=11.13 ; M_{\text {years participation }}=10.01, S D=8.40\right)$.

\section{Measures}

Risk-taking inventory. The two-factor seven-item RTI was administered as described previously.

Self-esteem. The Rosenberg self-esteem (RSE; Rosenberg, 1965) scale measures global self-esteem (e.g., I take a positive attitude toward myself). The RSE comprises 10 items rated on a five-point Likert scale $(1=$ not very true of me; $5=$ very true of me $)$. 
Personality. The 50-item IPIP (Goldberg, 1999), which is aligned with Costa and McCrae's (1992) five personality domains, measures neuroticism (e.g., Panic easily), extraversion (e.g., Am the life of the party), openness to experience (e.g., Enjoy hearing new ideas), agreeableness (e.g., Have a good word for everyone), and conscientiousness (e.g., Am always prepared $)$ on a five-point Likert scale $(1=$ very inaccurate $; 5=$ very accurate $)$.

Procedure. All participants completed a demographics questionnaire, as in Study 1, followed by the RSE, IPIP, and RTI. The online presentation of the inventories was the same as in Study 1 and took approximately 25 minutes to complete.

\section{Results}

RTI model fit. A good fit for the two-factor, seven-item RTI model was further confirmed (see Table 1). Factor-factor correlations confirmed the discriminant validity of the two-factor model (-.40).

Concurrent validity. As hypothesized, precautionary behaviors were significantly positively correlated with both self-esteem and conscientiousness. Also as hypothesized, deliberate risk-taking was significantly negatively correlated with conscientiousness and positively correlated with extraversion. The correlations are presented in Table 4.

\section{Discussion}

Study 3 further confirmed the factor structure of the RTI and the strong concurrent validity of each factor against measures of self-esteem, extraversion, and conscientiousness. In particular self-esteem was confirmed as more strongly related to precautionary behaviors, which suggests that this factor specifically taps into the preservation of the self.

\section{Study 4}

The first three studies demonstrated the good factor structure and concurrent validity of the RTI. The initial aims of the final study were to provide a final confirmation of the factor structure of the RTI and to test its predictive validity. Given that risk-taking behaviors 
in the high-risk sport domain could potentially be fatal to the participant and to others (Castanier et al., 2010a; Castanier, Le Scanff, \& Woodman, 2010b), we aimed to examine the predictive validity of the RTI using a retrospective measure of the mean annual number of accidents resulting in acute injuries experienced throughout the participant's involvement in their high-risk sport. As stated previously, we also sought to capture participants' experience of "close-calls." We hypothesized that deliberate risk taking would be positively correlated with both accidents and close-calls and that precautionary behaviors would be negatively related with these outcome measures. As age significantly influences risk-taking behaviors (Mata, Josef, Samanez-Larkin, \& Hertwig, 2011) we sought to examine whether these relationships would hold when controlling for age. We also modified the RTI so that an informant could rate a participant on his/her risk-taking behaviors with the hypothesis that participant and informant ratings would be positively correlated for each factor of the RTI. Finally, as precautionary behaviors might buffer the negative relationship between risk-taking and behavioral outcome, we sought to explore the potential interaction between the two RTI factors in predicting accidents and close-calls.

\section{Method}

Participants. The sample comprised 365 participants recruited using the same method and inclusion criteria as described in Study 1. Thirty-five participants did not meet the inclusion criteria. The final sample thus comprised 330 individuals (254 men, 76 women; $\left.M_{\text {age }}=31.28, S D=11.05 ; M_{\text {years participation }}=10.00, S D=8.09\right)$. The diversity of sports represented closely resembled that of the previous studies.

Informant sample. All 330 participants provided e-mail contact details for an informant. Of the 330 informants that we contacted, 74 provided data although 12 of these informants provided incomplete data. The final informant sample thus comprised 62 informants (43 men, 19 women; $M_{a g e}=31.15, S D=9.42 ; M_{\text {years participation with participant }}=5.85$, 
$S D=6.08)$. The low response rate is likely a result of the difficulty of obtaining responses from people who did not specifically choose to take part in the study. That is, they were solicited as a result of their name being given to the research team by the participants.

\section{Measures}

Risk-taking inventory. The RTI measured participants' deliberate risk-taking and precautionary behaviors in the high-risk domain.

Mean close-calls and Accidents. Participants reported the number of close-calls and accidents resulting in acute injuries (e.g., significant trauma, requiring hospitalization) experienced since beginning participation in their chosen high-risk sport. This number was then divided by the years' participation to provide an annual mean.

Informant RTI. All seven RTI items were modified to reflect the informant's perception of the participant's deliberate risk-taking (e.g., He/she actively seeks out dangerous situations) and precautionary behaviors (e.g., He/she takes time to check for potential hazards) in the high-risk domain. As with the original RTI, items were rated on a five-point Likert scale $(1=$ never $; 5=$ always $)$.

Procedure. All participants completed a demographics questionnaire, with additional items pertaining to the number of accidents or close-calls that they had experienced, and the RTI. The online presentation of the inventories mimicked that used in Study 1 and took approximately 15 minutes to complete. Additionally, participants provided the e-mail address of an informant with whom they had participated regularly in their chosen high-risk sport. Informants were then contacted and explained the nature of the study before being given a confidentiality agreement. If they chose to continue they completed a demographics questionnaire and the informant version of the RTI. The informant procedure took approximately 10 minutes to complete.

\section{Results}


RTI model fit. A good fit for the two-factor, seven-item RTI model was again confirmed (see Table 1). Factor-factor correlations further confirmed the discriminant validity of the two-factor model (-.27).

Mean accidents and close-calls. Participants' precautionary behaviors (PB) were significantly negatively correlated with both accidents and close-calls (see Table 5). When controlling for age, $\mathrm{PB}$ continued to significantly predict both accidents $\left(\Delta R^{2}=.01, p=.03\right)$ and close-calls $\left(\Delta R^{2}=.04, p<.001\right)$.

Participants' deliberate risk-taking behaviors (DRT) were significantly positively correlated with both accidents and close-calls (see Table 5). When controlling for age, DRT continued significantly to predict accidents $\left(\Delta R^{2}=.02, p=.02\right)$ but not close-calls $\left(\Delta R^{2}=.00\right.$, $p=.26)$.

In order to test the interaction between deliberate risk-taking and precautionary behaviors, we standardized both factors before creating an interaction term (Aiken \& West, 1991). Once the deliberate risk-taking and precautionary behaviors were entered into the model $\left(R^{2}=.03, p<.005\right)$, the interaction term accounted for no further significant proportion of variance in accidents $\left(\Delta R^{2}=.00, p=.54\right)$ or for close calls $\left(R^{2}=.06, p<.001\right.$ and $\Delta R^{2}=.00, p=.32$, respectively).

Informant ratings. Results revealed a significant positive correlation between the participant and informant ratings for both DRT and PB (see Table 5).

\section{Discussion}

In Study 4 the factor structure of the RTI was again supported. In Study 4 we also sought to test the predictive validity of the RTI by asking participants to self-report their experience of accidents and close-calls. To further validate the RTI we also asked informants to rate participants' degree of risk-taking. These tests of predictive validity confirmed that the RTI is a valid measure of risk-taking across high-risk sports. Both factors of the RTI 
significantly predicted accidents and close-calls. When age was included as a covariate, these associations largely remained significant. It is worth noting that the use of mean annual accidents and close-calls as an outcome measure of behavioral risk-taking is not without its limitations (see van Mechelen, Hlobil, \& Kemper, 1992). Furthermore, it has been well documented that injury recall is not always very accurate even over a 12-month period, which potentially makes periods longer than one year problematic in terms of recall accuracy (Gabbe, Finch, Bennell, \& Wajswelner, 2003; Jenkins, Earle-Richardson, TuckerSlingerland, \& May, 2002). There are two points that are perhaps worth considering in this respect. First, the predictive validity analyses yielded the expected results in the expected direction for each of the analyses, which somewhat mitigates the recall concern. That is, the predictive validity emerged despite potential recall inaccuracy. The second point may go some way to explain this robust finding: An injury incurred in a high-risk sport setting where the potential for severe injury or death is omnipresent (e.g., falling down a crevasse while ski mountaineering) is quite possibly a more emotionally memorable event than an injury in a more "traditional" activity or sport (e.g., spraining an ankle playing soccer). For example, an injury sustained in a high-risk sport may feel (and be) more akin to a near-death experience (e.g., falling from a rock face). Such emotionally intense experiences may well burn brighter in the participants' memory such that recall may be more vivid and accurate. As William James stated, "an experience may be so exciting as to almost leave a scar on the cerebral tissue" (1890, p. 670). Although this position is now considered rather too strong there is evidence that emotion-associated memory is indeed more accurate thanks to the amygdala activation that the emotion invokes (McGaugh \& Cahill, 2003). This dovetails well with the recent findings that high-risk sportspeople tend to engage in high-risk activities with the specific aim of regulating their emotions (e.g., Barlow, Woodman, \& Hardy, 2013; Woodman Hardy, Barlow, \& Le Scanff, 2010). Another potential limitation of the accidents and close- 
calls retrospective measure is that the direction of the relationship between risk-taking and accidents is difficult to establish via such a design. Specifically, future research will need to address the degree to which the RTI can predict risk-taking behavior and the degree to which the negative outcome of risk-taking behavior may affect risk-taking behavior.

\section{Summary and Concluding Discussion}

We sought to validate a measure of risk-taking in high-risk sports. Across four studies a two-factor risk-taking model of deliberate risk-taking and precautionary behaviors consistently fit the data well. Furthermore, the inventory revealed good concurrent and predictive validity.

High-risk sport research has been heavily reliant on the sensation seeking model (Zuckerman, 2007) despite recent advances based on agency and emotion regulation (e.g., Barlow et al., 2013; Castanier et al., 2010b; Cazenave, Le Scanff \& Woodman, 2007; Lafollie \& Le Scanff, 2007; Woodman et al., 2010). The reliance on the sensation seeking model is likely because high-risk sports participants have been viewed as a homogenous group of risktaking individuals within and across sports. The RTI will allow researchers to determine the extent to which this position is valid.

The moderated regression analyses revealed no support for the predictive validity of a deliberate $\times$ precautionary model. However, given the orthogonal nature of the two-factor model, future research would benefit from further exploring the potential interaction between the two RTI factors. For example, deliberately risky behaviors may be especially hazardous when accompanied by little concern for precautionary measures, but this may perhaps be more the case within some especially dangerous sports. Such a profile may also reflect a propensity to utilize the high-risk domain to regulate a difficulty with emotions (e.g., Woodman, Cazenave, \& Le Scanff, 2008; Woodman et al., 2010; Woodman, Huggins, Le Scanff, \& Cazenave, 2009). The interaction framework appears all the more worth pursuing 
in light of the clear discriminant validity of the RTI, with a maximum of $14 \%$ shared factorfactor variance across the four studies.

It is well established that risk-taking is associated with sex differences (Byrnes, Miller, \& Schafer, 1999) and age (e.g., Chaubey, 1974), and the data from the present studies were no exception. However, when age and sex differences were controlled the RTI remained a valid measure of risk-taking and continued to predict risk-taking outcomes (accidents and close-calls). In relation to the age effect, it is worth noting that we required participants to be at least 18 years old to participate in the studies. As such, the inventory remains to be validated with adolescent or younger samples.

The RTI is a fairly brief inventory that was intended to be applicable to a wide range of high-sports. Of course, the increase in generalizability that this approach affords comes at a potential cost in specific application. As such, users of the inventory are urged to consider adjunct sources of risk-taking behavior that will help to understand the behaviors of the sample of interest. The informant measure that we used in Study 4 appears particularly promising in this respect, as informants can provide another source of participants' risktaking behaviors - behaviors of which the participant may not be aware (Vazire, 2006).

Furthermore, a risk-taking inventory will only ever be an approximation of actual risk-taking behaviors. Asking informants to comment on or to rate a participant's behavior is one way of sourcing data from multiple sources, but such data will themselves remain subjective. Another avenue for future research is to think of ways in which dangerous behaviors can be conceptualized and measured within the high-risk domain. This is an important challenge because the perception of risk-taking as measured by the RTI (or any other inventory) may be markedly different to the reality of the objective danger to which participants may willingly or unwittingly expose themselves. Experience and skill are likely important moderators of any such relationships. That is, it is possible that the more 
experienced or skilled the participants, the less likely they are to engage with uncontrolled danger per se because they are more likely to be aware of such danger. Of course, such conjecture requires empirical attention.

We administered the RTI exclusively online, which could be viewed as a limitation. That is, despite its advantages, online data collection is not without its potential disadvantages. For example, the anonymous nature of the Internet may encourage individuals to participate with the express purpose of contaminating data or with a view to financial gain (Kraut et al., 2004) and it may increase the potential for self-selection bias (Thompson, Surface, Martin, \& Sanders, 2003), not least because non-response rate tracking was not recorded in the present studies (cf. Andrews, Nonnecke, \& Preece, 2003). These potential problems are of course not limited to the use of e-questionnaires, however, and apply equally to pen-and-paper surveys. Furthermore, as the confirmatory factor analyses yielded a strong fit to the data across four studies seems, this was likely not an issue in the present research. Finally, there appears to be no reason why the inventory would not be fit for pen-and-paper use.

In summary, risk-taking attitudes and behaviors can differ between individuals within and across high-risk sports and the Risk-Taking Inventory (RTI) was developed to measure such attitudes and behaviors. Across four studies the two-factor (deliberate risk-taking and precautionary behaviors) RTI was shown to be a valid measure of risk-taking behaviors. The RTI is the first valid measure of risk-taking attitude and behavior for high-risk sports and is significantly related to well-established personality constructs (e.g., impulsivity, sensation seeking, self-esteem, behavioral activation, behavioral inhibition, extraversion, conscientiousness) and to outcome measures (accidents and close-calls). It is also related to an informant version of the inventory. 


\section{References}

Aiken, L. S., \& West, S. G. (1991). Multiple regression: Testing and interpreting interactions. Newbury Park: Sage.

Andrews, D., Nonnecke, B., \& Preece, J. (2003). Electronic survey methodology: A case study in reaching hard-to-involve Internet users. International Journal of HumanComputer Interaction, 16, 185-210.

Arthur, W., \& Graziano, W. G. (1996). The five-factor model, conscientiousness, and driving accident involvement. Journal of Personality, 64, 593-618.

Barlow, M., Woodman, T., \& Hardy, L. (2013). Great expectations: Different high-risk activities satisfy different motives. Journal of Personality \& Social Psychology.

Baumeister, R. F., Heatherton, T. F., \& Tice, D. M. (1993). When ego threats lead to selfregulation failure: Negative consequences of high self-esteem. Journal of Personality \& Social Psychology, 64, 141-156.

Bentler, P. M. (1990). Comparative fit indexes in structural models. Psychological Bulletin, $107,238-246$.

Butler, G. K. L., \& Montgomery, A. M. J. (2004). Impulsivity, risk taking and recreational 'ecstasy’ (MDMA) use. Drug and Alcohol Dependence, 76, 55-62.

Breivik, G. (1996). Personality, sensation seeking and risk taking among Everest climbers. International Journal of Sport Psychology, 27, 308-320.

Byrne, B. M. (1998). Structural equation modeling with LISREL, PRELIS, and SIMPLIS: Basic concepts, applications and programming. London, England: Lawrence Erlbaum.

Byrnes, J P, Miller, D C., Schafer, W. D. (1999). Gender differences in risk taking: A metaanalysis. Psychological Bulletin, 125, 367-383. 
Carver, C. S., \& White, T. L. (1994). Behavioral inhibition, behavioral activation, and affective responses to impending reward and punishment: The BIS/BAS scales. Journal of Personality \& Social Psychology, 67, 319-333.

Castanier, C., Le Scanff, C., \& Woodman, T. (2010a). Who takes risks in high-risk sports? A typological personality approach. Research Quarterly for Exercise and Sport, 81, 478-483.

Castanier, C., Le Scanff, C., \& Woodman, T. (2010b). Beyond sensation seeking: Affect regulation as a framework for predicting risk-taking behaviors in high-risk sport. Journal of Sport \& Exercise Psychology, 32, 731-738.

Cazenave, N., Le Scanff, C., \& Woodman, T. (2007). Psychological profiles and emotional regulation characteristics of women engaged in risk-taking sports. Anxiety, Stress, and Coping, 20, 421-435.

Celsi, R. L., Rose, R. L., \& Leigh, T. W. (1993). An exploration of high-risk leisure consumption through skydiving. Journal of Consumer Research, 20, 1-23.

Chaubey, N. P. (1974). Effect of age on expectancy of success and on risk-taking behavior. Journal of Personality \& Social Psychology, 29, 774-778.

Cherpitel, C. J., Meyers, A. R., \& Perrine, M. W. (1998). Alcohol consumption, sensation seeking and ski injury: a case-control study. Journal of Studies on Alcohol, 59, 216221.

Cogan, N., \& Brown, R. I. F. (1999). Metamotivational dominance, states and injuries in risk and safe sports. Personality and Individual Differences, 27, 503-518.

Costa, P. T., \& McCrae, R. R. (1992). Revised NEO personality inventory manual. Odessa, FL: Psychological Assessment Resources.

Creswell, J. W. (2008). Research design: Qualitative, quantitative, and mixed methods approaches. London, England: Sage. 
Donohew, L., Zimmerman, R. S., Cupp, P. S., Novak, S., Colon, S., \& Abell, R. (2000). Sensation seeking, impulsive decision-making, and risky sex: Implications for risktaking and design of interventions. Personality and Individual Differences, 28, 10791091.

Gabbe, B. J., Finch, C. F., Bennell, K. L., \& Wajswelner, H. (2003). How valid is a self reported 12-month sports injury history? British Journal of Sports Medicine, 37, 545547.

Goldberg, L. R. (1999). A broad-bandwidth, public domain, personality inventory measuring the lower-level facets of several five-factor models. In I. Mervielde, I. Deary, F. De Fruyt, \& F. Ostendorf (Eds.), Personality Psychology in Europe, Vol. 7 (pp. 7-28). Tilburg, The Netherlands: Tilburg University Press.

Goodwin, J. C. (2009). Research in psychology: methods and design (6 $6^{\text {th }}$ ed.). New York: Wiley.

Gray, J. A. (1972). The psychophysiological basis of introversion-extraversion: A modification of Eysenck's theory. In V. D. Nebylitsyn \& J. A. Gray (Eds.), The biological bases of individual behavior (pp.182-205). San Diego, CA: Academic Press.

Gray, J. A. (1981). A critique of Eysenck's theory of personality. In H. J. Eysenck (Ed.), A model for personality (pp. 246-276). Berlin: Springer-Verlag.

Gutman, B., \& Frederick, S. (2003). Being extreme: Thrills and dangers in the world of highrisk sports. New York, NY: Citadel press.

Hill, E. M., \& Gick, M. L. (2011). The big five and cervical screening barriers: Evidence for the influence of conscientiousness, extraversion and openness. Personality and Individual Differences , 50, 5662-5667. 
Hoyle, R. H., Stephenson, M. T., Palmgreen, P., Lorch, E. P., \& Donohew, R. L. (2002). Reliability and validity of a brief measure of sensation seeking. Personality and Individual Differences, 32, 401-414.

James, W. (1890). Principles of psychology. New York: Henry Holt.

Jenkins, P., Earle-Richardson, G., Tucker-Slingerland, D., \& May, J. (2002). Time dependent memory decay. American Journal of Industrial Medicine, 41, 98-101.

Joinson, A. (1999). Social desirability, anonymity, and internet-based questionnaires. Behavior Research Methods, Instruments, and Computers, 31, 433-438.

Jöreskog, K. G. (1993). Testing structural equation models. In K. A. Bollen, \& J. S. Long (Eds.), Testing structural equation models (pp. 294-316). Newbury Park, CA: Sage.

Jöreskog, K.G. \& Sörbom, D. (2003). LISREL 8.54 for Windows [Computer Software]. Lincolnwood, IL: Scientific Software International, Inc.

Kontos, A. P. (2004). Perceived risk, risk taking, estimation of ability and injury among adolescent sport participants. Journal of Paediatric Psychology, 29, 447-455.

Kraut, R., Olson, J., Banaji, M., Bruckman, A., Cohen, J., \& Couper, M. (2004). Psychological research online. American Psychologist, 59, 105-117.

Lafollie, D., \& Le Scanff, C. (2007). Détection des personnalités à risque dans les sports à sensations fortes. [Detection of high-risk personalities in risky sports]. L'Encéphale, $33,135-141$.

Little, R. J. A., \& Rubin, D. B. (1987). Statistical analysis with missing data. New York: Wiley.

Llewellyn, D. J., \& Sanchez, X. (2008). Individual differences and risk taking in rock climbing. Psychology of Sport and Exercise, 9, 413-426. 
Magid, V., \& Colder, C. R. (2007). The UPPS Impulsive Behavior Scale: Factor structure and associations with college drinking. Personality and Individual Differences, 43, 1927-1937.

Mangunkusumo, R. T., Moorman, P. W., van den Berg-de Ruiter, A. E., Van Der Lei, J., De Koning, H. J., \& Raat, H. (2005). Internet-administered adolescent health questionnaires compared with a paper version in a randomized study. Journal of Adolescent Health, 36, 70.e1-70.e6.

Mata, R., Josef, A. K., Samanez-Larkin, G. R., \& Hertwig, R. (2011). Age differences in risky choice: A meta-analysis. Annals of the New York Academy of Sciences, 1235, $18-29$.

McGaugh, J. L., \& Cahill, L. (2003). Emotion and memory: Central and peripheral contributions. In R. J. Davidson, K. R. Scherer, \& H. H. Goldsmith (Eds.), Handbook of affective sciences (pp. 93-116). NewYork: Oxford University Press.

Mount, M. K., Barrick, M. R., \& Strauss, J. P. (1994). Validity of observer ratings of the big five personality factors. Journal of Applied Psychology, 79, 272-280.

Musolino, R. F., \& Hershenson, D. B. (1977). Avocational sensation seeking in high and low risk-taking occupations. Journal of Vocational Behavior, 10, 358-365.

Nagoshi, C. T., Wilson, J. R., \& Rodriguez, L. A. (1991). Impulsivity, sensation seeking, and behavioral and emotional responses to alcohol. Alcoholism: Clinical \& Experimental Research, 15, 661-667.

Nietzsche, F. (1882/2001). The gay science. Cambridge: Cambridge University Press.

Oh, I., Wang, G., \& Mount, M. K. (2011). Validity of observer ratings of the five-factor model of personality traits: A meta-analysis. Journal of Applied Psychology, 96, 762773.

Pain, M. T. G., \& Pain, M. A. (2005). Risk taking in sport. Lancet, 366, 33-34. 
Paquette, L., Lacourse, E., Bergeron, J. (2009). Construction d'une échelle de prise de risques et validation auprès d'adolescents pratiquant un sport alpin de glisse [Construction and validation of a risk-taking scale for adolescent practitioners of Alpine ski sports]. Canadian Journal of Behavioral Sciences, 41, 133-142.

Peng, C-Y. J., Harwell, M., Liou, S-M., \& Ehman, L. H. (2006). Advances in missing data methods and implications for educational research. In S. Sawilowsky (Ed.), Real data analysis (pp. 31-78). Greenwich, CT: Information Age.

Peterson, R. A., \& Kim, Y. (2013). On the relationship between coefficient alpha and composite reliability. Journal of Applied Psychology, 98, 194-198.

Rhemtulla, M., Brosseau-Liard, P. É., \& Savalei, V. (2012). When can categorical variables be treated as continuous? A comparison of robust continuous and categorical SEM estimation methods under suboptimal conditions. Psychological Methods, 17, 354373.

Rohrmann, B. (1998). The risk notion - epistemological and empirical considerations. In M. G. Stewart, \& R. E. Melchers (Eds.), Integrative risk assessment (pp. 39-46). Rotterdam: Balkema.

Rosenberg, M. (1965). Society and the Adolescent Self-Image. Princeton, NJ: Princeton University Press.

Slanger, E., \& Rudestam, K. E. (1997). Motivation and disinhibition in high risk sports: Sensation seeking and self-efficacy. Journal of Research in Personality, 31, 355-374.

Stanton, J. M. (1998). An empirical assessment of data collection using the internet. Personnel Psychology, 51, 709-726.

Steiger, J. H. (1980). Tests for comparing elements of a correlation matrix. Psychological Bulletin, 87, 245-251. 
Steiger, J. H., \& Lind, J. C. (1980). Statistically-based tests for the number of factors. Paper presented at the Annual Spring Meeting of the Psychometric Society, Iowa City, IA.

Tabachnick, B. G., \& Fidell, L. S. (2001). Using multivariate statistics. London, UK: Allyn and Bacon.

Thompson, L. F., Surface, E. A., Martin, D. L., \& Sanders, M. G. (2003). From paper to pixels: Moving personnel surveys to the Web. Personnel Psychology, 56, 197-227.

Tucker, L. R., \& Lewis, C. (1973). A reliability coefficient for maximum likelihood factor analysis. Psychometrika, 38, 169-180.

van Mechelen, W., Hlobil, H., \& Kemper, H. C. (1992). Incidence, severity, aetiology and prevention of sports injuries. A review of concepts. Sports Medicine, 14, 82-99.

Vazire, S. (2006). Informant reports: A cheap, fast, and easy method for personality assessment. Journal of Research in Personality, 40, 472-481.

Vollrath, M., \& Torgersen, S. (2002). Who takes health risks? A probe into eight personality types. Personality and Individual Differences, 32, 1185-1198.

Wallace, J. C., \& Vodanovich, S. J. (2003). Workplace safety performance: Conscientiousness, cognitive failure, and their interaction. Journal of Occupational Health Psychology, 8, 316-327.

Whiteside, S. P., \& Lynam, D. R. (2001). The five factor model and impulsivity: Using a structural model of personality to understand impulsivity. Personality and Individual Differences, 30, 669-689. doi:10.1016/S0191-8869(00)00064-7

Woodman, T., Cazenave, N., \& Le Scanff, C. (2008). Skydiving as emotion regulation: The rise and fall of anxiety is moderated by alexithymia. Journal of Sport \& Exercise Psychology, 30, 424-433. 
Woodman, T., Hardy, L., Barlow, M., \& Le Scanff, C. (2010). Motives for prolonged engagement high-risk sports: An agentic emotion regulation perspective. Psychology of Sport and Exercise, 11, 345-352. DOI: 10.1016/j.psychsport.2010.04.002

Woodman, T., Huggins, M., Le Scanff, C., \& Cazenave, N. (2009). Alexithymia determines the anxiety experienced in skydiving. Journal of Affective Disorders, 116, 134-138. DOI: $10.1016 /$ j.jad.2008.11.022

Wynd, C.A., Schmidt, B., \& Schaefer, M.A. (2003). Two quantitative approaches for estimating content validity. Western Journal of Nursing Research, 25, 508-518.

Zuckerman, M. (1979). Sensation seeking: Beyond the optimal level of arousal. Hillsdale, NJ: Erlbaum.

Zuckerman, M. (1994). Behavioral expressions and biosocial bases of sensation seeking. New York, NY: Cambridge University Press.

Zuckerman, M. (2007). Sensation seeking and risky behavior. Washington, DC: American Psychological Association. 
Table 1.

Model fit indices for: (a) The data set of complete cases (following list-wise deletion); and (b) The data set with full information maximum likelihood estimations, for the Risk Taking Inventory in Studies 1 - 4.

(a) Model fit indices for the data set of complete cases (following list-wise deletion)

\begin{tabular}{|c|c|c|c|c|c|c|c|}
\hline & & $\begin{array}{l}\text { Stud } \\
(n=3\end{array}$ & & & $\begin{array}{c}\text { Study } 2 \\
(n=490)\end{array}$ & $\begin{array}{c}\text { Study } 3 \\
(n=221)\end{array}$ & $\begin{array}{c}\text { Study } 4 \\
(n=330)\end{array}$ \\
\hline & $\begin{array}{l}\text { Single-factor model } \\
\text { DRT (10 items) }\end{array}$ & $\begin{array}{l}\text { Single-factor model } \\
P B(10 \text { items })\end{array}$ & $\begin{array}{c}\text { Two-factor model } \\
\text { (eight items per factor) }\end{array}$ & $\begin{array}{l}\text { Two-factor } \\
\text { seven-item } \\
\text { model }\end{array}$ & $\begin{array}{l}\text { Two-factor } \\
\text { seven-item } \\
\text { model }\end{array}$ & $\begin{array}{l}\text { Two-factor } \\
\text { seven-item } \\
\text { model }\end{array}$ & $\begin{array}{l}\text { Two-factor } \\
\text { seven-item } \\
\text { model }\end{array}$ \\
\hline$S-B \chi^{2}(\mathrm{df})$ & $108.22(35)$ & $108.22(35)$ & $287.58(103)$ & $19.28(13)$ & $7.66(13)$ & $22.11(13)$ & $18.96(13)$ \\
\hline CFI & .96 & .93 & .93 & .99 & 1.00 & .96 & .98 \\
\hline NNFI & .94 & .91 & .91 & .98 & 1.00 & .94 & .97 \\
\hline RMSEA & .08 & .08 & .08 & .04 & .00 & .06 & .04 \\
\hline SRMR & .05 & .06 & .08 & .05 & .02 & .05 & .05 \\
\hline
\end{tabular}

(b) Model fit indices for the data set with full information maximum likelihood estimations

\begin{tabular}{|c|c|c|c|c|c|c|c|}
\hline & \multicolumn{4}{|c|}{$\begin{array}{c}\text { Study 1 } \\
(n=366)\end{array}$} & $\begin{array}{c}\text { Study } 2 \\
(n=509)\end{array}$ & $\begin{array}{c}\text { Study } 3 \\
(n=244)\end{array}$ & $\begin{array}{l}\text { Study } 4^{3} \\
(n=330)\end{array}$ \\
\hline & $\begin{array}{l}\text { Single-factor model } \\
\text { DRT (10 items) }\end{array}$ & $\begin{array}{l}\text { Single-factor model } \\
\text { PB (10 items })\end{array}$ & $\begin{array}{c}\text { Two-factor model } \\
\text { (eight items per factor) }\end{array}$ & $\begin{array}{c}\text { Two-factor } \\
\text { seven-item } \\
\text { model }\end{array}$ & $\begin{array}{l}\text { Two-factor } \\
\text { seven-item } \\
\quad \text { model }\end{array}$ & $\begin{array}{l}\text { Two-factor } \\
\text { seven-item } \\
\text { model }\end{array}$ & $\begin{array}{c}\text { Two-factor } \\
\text { seven-item } \\
\text { model }\end{array}$ \\
\hline$S-B \chi^{2}(\mathrm{df})$ & $103.59(35)$ & $122.98(35)$ & $293.21(103)$ & $18.90(13)$ & $7.22(13)$ & $29.27(13)$ & $18.96(13)$ \\
\hline CFI & .97 & .94 & .94 & .99 & 1.00 & .96 & .98 \\
\hline NNFI & .96 & .92 & .92 & .98 & 1.00 & .93 & .97 \\
\hline RMSEA & .08 & .09 & .07 & .04 & .00 & .07 & .04 \\
\hline
\end{tabular}

DRT $=$ Deliberate Risk Taking; PB = Precautionary Behaviors; S-B = Satorra-Bentler; CFI = Comparative Fit Index; NNFI = Non-Normed Fit Index; RMSEA = Root Mean Square Error of Approximation; SRMR = Standardized Root Mean Residual.

\footnotetext{
${ }^{3}$ FIML results mirror those in Table 1(a), as there were no missing data in Study 4.
} 
Table 2.

Item-factor loadings for the two subscales from the Risk-taking inventory (RTI) in Study 1.

\begin{tabular}{lc}
\hline Deliberate Risk-Taking (DRT) & Item-factor loading \\
\hline I deliberately put myself in danger & .77 \\
It's like gambling, you can't win unless you try it & .60 \\
I actively seek out dangerous situations & .83 \\
\hline Precautionary Behaviors (PB) & .60 \\
\hline I take time to check conditions (e.g., weather) & .45 \\
I check any gear/equipment that I borrow & .66 \\
I am aware of the nearest help and first aid & .73 \\
I take time to check for potential hazards &
\end{tabular}


Table 3.

The relationship between the RTI and the BIS/BAS, BSSS and UPPS in Study 2.

\begin{tabular}{llcccccc}
\hline Scale & Subscale & DRT & PB & Alpha & CR & Mean & $S D$ \\
\hline RTI & Deliberate Risk Taking (DRT) & - & $-.14^{* *}$ & .71 & .72 & 7.21 & 2.64 \\
RTI & Precautionary Behaviors (PB) & $-.14^{* *}$ & - & .62 & .64 & 17.46 & 2.16 \\
\hline BIS & Behavioral Inhibition & -.02 & -.05 & $.40^{4}$ & .50 & 16.97 & 2.47 \\
BAS & Reward Response & $.24^{* *}$ & .01 & .69 & .69 & 9.09 & 2.03 \\
BAS & Drive & $.27^{* *}$ & $.09^{*}$ & .79 & .80 & 8.82 & 2.15 \\
BAS & Fun Seeking & $.32^{* *}$ & $.10^{*}$ & .72 & .73 & 7.78 & 2.04 \\
\hline BSSS & Experience Seeking & $.19^{* *}$ & .07 & $.54^{5}$ & .54 & 8.08 & 1.60 \\
BSSS & Boredom Susceptibility & $.26^{* *}$ & -.02 & .40 & .40 & 7.31 & 1.54 \\
BSSS & Thrill and Adventure & $.36^{* *}$ & .01 & .62 & .85 & 6.38 & 2.15 \\
BSSS & Disinhibition & $.30^{* *}$ & -.05 & .64 & .84 & 5.86 & 2.09 \\
BSSS & Total & $.37^{* *}$ & .00 & .80 & .80 & 27.63 & 5.72 \\
\hline UPPS & Urgency & $.19^{* *}$ & $-.20^{* *}$ & .80 & .84 & 23.28 & 5.23 \\
UPPS & Premeditation & $-.32^{* *}$ & $.23^{* *}$ & .83 & .83 & 32.43 & 5.21 \\
UPPS & Perseverance & $-.09^{*}$ & $.25^{* *}$ & $.48^{6}$ & .58 & 31.13 & 3.43 \\
UPPS & Sensation Seeking & $.33^{* *}$ & $.15^{* *}$ & .82 & .81 & 36.99 & 6.39 \\
\hline & $* p<.05, * *<.01$ & & & & & &
\end{tabular}

Note: $\mathrm{DRT}=$ Deliberate Risk-taking; $\mathrm{PB}=$ Precautionary Behaviours; $\mathrm{CR}=$

Composite Reliability; RTI = Risk-Taking Inventory; BIS/BAS = Behavioral Inhibition

System/Behavioral Activation System; BSSS = Brief Sensation Seeking Scale; UPPS =

UPPS impulsivity scale.

${ }^{4}$ Examination of the inter-item correlation matrix indicated that item 2 and item 7 had strong inverse correlations with the other items, which contributed to this low alpha and composite reliability. When we removed these two items the internal reliability improved ( $\alpha$ $=.74 ; \mathrm{CR}=.75$ ) but the pattern of correlations remained the same.

${ }^{5}$ The individual subscales of the BSSS demonstrated low internal reliability. However, this is not surprising given that the BSSS subscales comprise only two items (cf. Creswell, 2008). The overall alpha was acceptable.

${ }^{6}$ Examination of the inter-item correlation matrix indicated that item 10 strongly contributed to the low reliability. Although removal of this item improved the subscale internal reliability $(\alpha=.63)$, the pattern of results remained the same. 
Table 4.

The relationship between the RTI and the RSE and the IPIP subscales in Study 3.

\begin{tabular}{llcccccc}
\hline Scale & Subscale & DRT & PB & Alpha & CR & Mean & $S D$ \\
\hline RTI & Deliberate Risk Taking (DRT) & - & $-.31^{* *}$ & .63 & .64 & 7.02 & 2.53 \\
RTI & Precautionary Behaviors (PB) & $-.31^{* *}$ & - & .64 & .65 & 16.93 & 2.52 \\
\hline RSE & Self-esteem & -.11 & $.21 * *$ & .87 & .88 & 32.50 & 4.87 \\
\hline IPIP & Neuroticism & .03 & -.07 & .82 & .83 & 23.91 & 6.91 \\
IPIP & Extraversion & $.19 * *$ & .00 & .86 & .86 & 34.92 & 6.67 \\
IPIP & Conscientiousness & $-.24 * *$ & $.21 * *$ & .81 & .82 & 35.04 & 6.28 \\
IPIP & Openness & -.00 & .06 & .71 & .72 & 37.54 & 5.61 \\
IPIP & Agreeableness & -.09 & .08 & .78 & .78 & 37.06 & 5.72 \\
\hline & $* p<.05, * * p<.01$ & & & & & &
\end{tabular}

Note: $\mathrm{DRT}=$ Deliberate Risk-taking; $\mathrm{PB}=$ Precautionary Behaviors; $\mathrm{CR}=$ Composite

Reliability; RSE = Rosenberg Self-Esteem; IPIP = International Personality Item Pool. 
Table 5.

The relationship between the RTI, Informant Assesment of Risk Taking (IRTI), Accidents, and Close-calls in Study 4.

\begin{tabular}{lcccccc}
\hline Variable & DRT & PB & Alpha & CR & Mean & $S D$ \\
\hline Deliberate Risk Taking (DRT) & - & $-.37^{* *}$ & .68 & .69 & 6.98 & 2.68 \\
Precautionary Behaviors (PB) & $-.37^{* *}$ & - & .68 & .69 & 16.93 & 2.64 \\
\hline $\begin{array}{l}\text { Informant Assessment of participant } \\
\text { Deliberate Risk Taking }\end{array}$ & $.31^{* *}$ & -.17 & .71 & .72 & 8.39 & 2.71 \\
$\begin{array}{l}\text { Informant Assessment of participant } \\
\text { Precautionary Behaviors }\end{array}$ & -.20 & $.28^{* *}$ & .82 & .82 & 16.74 & 2.99 \\
\hline Age & $-.33^{* *}$ & $.19^{* *}$ & - & - & 31.28 & 11.05 \\
\hline Accidents & $.16^{* *}$ & $-.13^{* *}$ & - & - & 0.74 & 1.33 \\
Close-calls & $.14^{* *}$ & $-.24^{* *}$ & - & - & 5.87 & 9.82 \\
\hline
\end{tabular}

Note: $* p<.05 ; * * p<.01 ; \mathrm{DRT}=$ Deliberate Risk-taking; PB = Precautionary

Behaviors; $\mathrm{CR}=$ Composite Reliability 